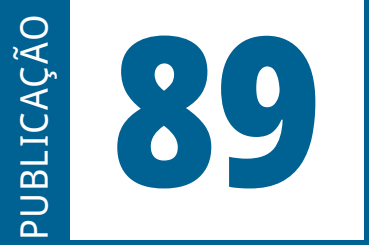

ISSN: 0101-9562

ISSN ELETRÔNICO: 2177-7055

SEQÜÊNCIA

Publicação do

Estudos jurídicos

e políticos

Programa de Pós-Graduação em Direito da UFSC

VOLUME 42 - ANO 2021 
SEQUÊNCIA - ESTUDOS JURÍDICOS E POLÍTICOS é uma publicação temática e de periodicidade quadrimestral, editada pelo Programa de Pós-Graduação Stricto Sensu em Direito da Universidade Federal de Santa Catarina - UFSC.

SEQUÊNCIA - ESTUDOS JURÍDICOS E POLÍTICOS is a thematic publication, printed every four months, edited by the Program in law of the Federal University of Santa Catarina - UFSC.

Versão eletrônica: http://www.periodicos.ufsc.br/index.php/sequencia

A publicação é indexada nas seguintes bases de dados e diretórios/

The Publication is indexed in the following databases and directories:

Base OJS

Base PKP

CCN (Catálogo Coletivo Nacional)

Dialnet

DOAJ (Directory of Open Access Journals)

EBSCOhost

Genamics Journalseek

ICAP (Indexação Compartilhada de Artigos de Periódicos)

Latindex

LivRe!

OJS
PKP
Portal de Periódicos UFSC
Portal do SEER
ProQuest
SciELO
Sherpa/Romeo
Sumarios.org
ULRICH'S
vLex

Ficha catalográfica

Seqüência: Estudos jurídicos e políticos. Universidade Federal de Santa Catarina.

Programa de Pós-Graduação em Direito. n.1 (janeiro 1980)-.

Florianópolis: Fundação José Boiteux. 1980-.

Publicação contínua

Resumo em português e inglês

Versão impressa ISSN 0101-9562

Versão on-line ISSN 2177-7055

1. Ciência jurídica. 2. Teoria política. 3. Filosoia do direito. 4. Periódicos.

I. Universidade Federal de Santa Catarina. Programa de Pós-graduação em

Direito

CDU 34(05)

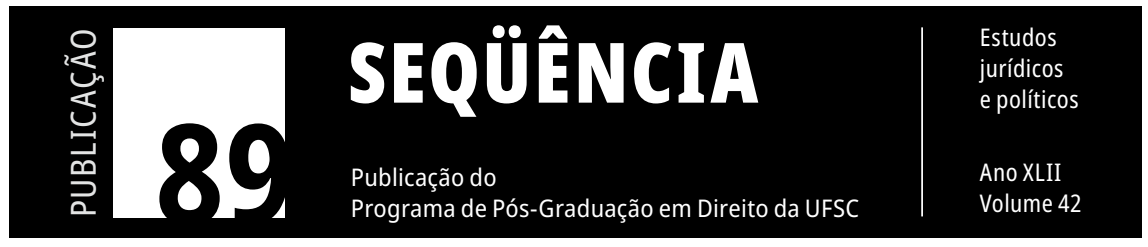




\title{
A Autodeterminação dos Povos na Corte Internacional de Justiça: Aproximações possíveis às Opiniões Consultivas sobre 0 Sudoeste Africano e o Saara Ocidental
}

\author{
Self-Determination in the International Court of \\ Justice: Possible Approaches to Advisory Opinions \\ on Southwest Africa and Western Sahara
}

\begin{abstract}
Adriano Alberto Smolarek ${ }^{1}$
${ }^{1}$ Universidade Estadual de Ponta Grossa, Ponta Grossa, Brasil João Irineu de Resende Miranda ${ }^{2}$ Universidade Estadual de Ponta Grossa, Ponta Grossa, Brasil
\end{abstract}

RESUMO: O presente artigo objetiva identificar através da pesquisa bibliográfica e documental e utilizando do método dedutivo, se existiria alguma indicação de percurso hermenêutico ou postura adotada pela Corte nas decisões emitidas sobre autodeterminação dos povos. Assim, o faz a partir de Opiniões Consultivas em casos temporal e circunstancialmente distintos, relativos a processos de descolonização como reflexos da sedimentação do Princípio da Autodeterminação dos Povos. São eles o Caso do Sudoeste Africano e o Caso do Saara Ocidental. Ao fim são propostos dois padrões jurisprudenciais relacionados aos casos construídos pela Corte, um legalista e outro material.

PalavRAS-CHAVE: Autodeterminação dos Povos - Corte Internacional de Justiça Opinião Consultiva.

ABSTRACT: This article aims to identify through bibliographical and documentary research through the deductive method, whether there is any indication of a hermeneutic path or posture adopted by the Court in the decisions issued on self-determination. Thus, based on Advisory Opinions prolated by the Court, in temporally and circumstantially distinct cases, concerning decolonization processes 
as a sedimentation of the Principle of Self-Determination reflex. They are the Case of Southwest Africa and the Western Sahara Case. At the end, two jurisprudential standards related to the cases constructed by the Court are proposed, one legalistic and the other material.

KEYWORDS: Self-Determination - International Court of Justice - Advisory Opinion.

\section{INTRODUÇÃO}

O Princípio da Autodeterminação dos Povos, tal qual hoje se define, é o reflexo de um momento singular na história mundial. Desde o Século XVI, a ocupação, a "colonização" e o assenhoreamento de imensas áreas do globo, mal definidas pela desnecessária regulação do multifacetário mundo tribal e pluricultural de alguns locais do planeta, foram o cenário perfeito para o espólio de riquezas naturais, vulneração e subversão de culturas, imposição de outras, e principalmente, para a submissão político-administrativa de povos e nações ao interesse estrangeiro. Na maioria dos casos, em contrariedade com os anseios do povo autóctone. O tema embora pareça longínquo e desconexo com a realidade do mundo globalizado, mostra-se próximo e cada dia mais expõe seus reflexos.

Utilizada primeiramente como argumento político e ideológico, a autodeterminação dos povos só foi verdadeiramente encampada pela ordem internacional a partir da Segunda Guerra Mundial, num intento de deslegitimar a ocupação territorial e legitimar o processo de insurgência através dos Movimentos de Libertação Nacional do jugo colonial. O Princípio da Autodeterminação é acolhido via resolução pela Organização das Nações Unidas e se consagra como argumento legitimador do processo de independência de razoável quantidade dos países do globo. Este processo, materializado nas resoluções 1514 e 1541, ambas da XV Assembleia Geral das Nações Unidas (1960), não será objeto direto do que aqui se debruça.

No entanto, embora alçado ao ambiente internacional, o princípio suscitava em vista da amplitude política e jurídica, inúmeras 
dúvidas relativas, principalmente, à sua implicação como base para a materialização da independência de novos estados e também no aspecto posteriormente trazido pelos Pactos Internacionais dos Direitos Civis e Políticos e Econômicos, Sociais e Culturais de 1966, cuja aplicação se direcionou à individualidade do ser humano, ator social. Tais interpretações, frutos de uma conjuntura marcada pelo contexto da guerra fria expôs dúvidas, sobretudo no viés relacionado às nações ansiosas por materializar sua independência e no relativo ao limite da eficácia e dos mecanismos de execução do princípio.

Por sensível, o tema requeria da expertise jurisdicional que pudesse demonstrar através de sua manifestação, uma equalização hermenêutica dos anseios das potências e a cristalização do princípio condutor ao anseio de liberdade das nações submetidas. Tornava-se necessária a implicação, ainda que indireta, de um órgão jurisdicional com vocação universal para tal feito.

Com a instituição da Corte Internacional de Justiça, a ONU passa a deter nos mesmos moldes de sua antecessora - Sociedade das Nações -, um órgão jurisdicional para resolver demandas existentes com base no Direito Internacional. Sendo possível que, por vezes, a autodeterminação dos povos se entrecruzasse com o exercício jurisdicional desta, resultando na emissão de posicionamentos e a constituir elementos para a discussão do princípio. Embora sejam raros os momentos que a autodeterminação penetrou no campo judicial, sua análise centra-se, segundo Malcolm Shaw (2012, p. 189), principalmente nos pareceres consultivos do caso Sudoeste Africano (Namíbia) e Saara Ocidental, tornando-os naturais paradigmas para a discussão em torno da temática em ambiente jurisdicional. Assim, pode-se afirmar que o mote questionador que nos levou a construir a pesquisa pode ser atribuída a seguinte pergunta: existiria alguma indicação de percurso hermenêutico ou postura adotada pela Corte nas decisões emitidas sobre autodeterminação dos povos?

Isto posto, diante das buscas realizadas no site oficial da Corte, foram encontradas diversas Opiniões Consultivas correlatas. 
Optou-se por analisar os casos denominados "A Questão Relativa ao Status Internacional do Sudoeste Africano", cujo processo de descolonização fora completamente realizado (optou-se por analisar as três diferentes Opiniões Consultivas que envolvem a temática do Sudoeste Africano - atual Namíbia, entre as décadas de 50 e 70); e a "Questão relativa ao Saara Ocidental" (1975), que a despeito de uma clara e contundente dicção jurisdicional, mantém latente um impasse que perpetua a pendência de sua implementação.

Tratam-se de casos complexos, distintos entre si temporal e circunstancialmente, e que demonstram graus de implementação diversos, mas que consistem, conforme Malcolm Shaw (2012, p.189) nas decisões paradigmáticas relativas ao tema, tendo em vista que em diversos outros casos (Caso sobre as consequências legais da construção de um muro nos Territórios Palestinos Ocupados - 2004; Caso Conformidade da Declaração Unilateral de Independência de Kossovo com o Direito Internacional - 2010; Consequências jurídicas da Separação do Arquipélago de Chagos de Maurício - 2019) não estava presente o contexto descolonizatório que consiste no recorte deste trabalho.

Antes, porém, de debruçar sobre os casos, são expostos temas introdutórios à temática como a natureza da Autodeterminação dos Povos como discurso político e jurídico ao longo do tempo, sem exaurir a análise, tendo em vista o recorte temporal dos casos que são objeto do trabalho. Após, se discorrerá sobre a Corte Internacional de Justiça e sua jurisdição consultiva, explanando sobre o alcance e o escopo de tais manifestações, para só então passar aos exemplos casuísticos.

Assim, o escrito objetiva identificar indícios de percurso hermenêutico de aplicação do Princípio da Autodeterminação dos Povos na jurisprudência da Corte Internacional de Justiça ao longo do seu exercício jurisdicional. Para alcançar o objetivo almejado, se utilizará do método dedutivo sustentado por pesquisa bibliográfica e documental, que consiste em meio apto para definir, resolver ou rediscutir, não só problemas científicos já conhecidos, mas também mecanismo que 
permite ao cientista realizar o exame de um tema sob novo enfoque de abordagem, possibilitando alcançar soluções inovadoras (LAKATOs, 2003). A pesquisa bibliográfica caminhará junto da análise documental indireta que se prestará à análise de fontes primárias de natureza internacional, como tratados e convenções e de manifestações jurisprudenciais da CIJ ao que se utilizará de metodologia própria, para esta última, da análise jurisprudencial no viés proposto por Freitas Filho e Lima (2010), que a descrevem como uma metodologia que possibilita coletar decisões de um ou diversos decisores, sobre um determinado problema jurídico, com o objetivo de identificar um momento decisório, realizar um retrato do "estado da arte" sobre o assunto.

A Análise de Jurisprudência permite a identificação da posição dos decisores ou mesmo de um tribunal em relação ao problema e a suas eventuais inclinações em relação às demais possibilidades de solução que, porventura, não tenham sido adotadas. Ainda, segundo os mesmos pesquisadores tal metodologia proporciona a possibilidade de organizar informações relativas a decisões proferidas em um determinado contexto; verificar a coerência decisória em contexto pré-determinado e produzir uma explicação do sentido das decisões (Freitas Filho; Lima, 2010). Para tanto a metodologia proposta se baseia na pesquisa exploratória, doutrinária e jurisprudencial acerca do tema, que permite a realização de um recorte objetivo, uma seleção conceitual do campo discursivo em que se encontra o problema. Por fim, deve ser definido o recorte institucional que seja justificado pela pertinência do tema analisado e a relevância decisória daquele órgão jurisdicional para o tema (Freitas Filho; Lima, 2010). Neste sentido o percurso metodológico torna clara a definição do campo discursivo do artigo que se refere à autodeterminação dos povos; o recorte institucional que está baseado na Corte Internacional de Justiça, justificando a pertinência do tema e a relevância institucional através do recorte proposto nos dois casos analisados.

Ainda, como marco teórico da análise da autodeterminação dos povos utiliza-se de trabalhos de autores, em sua maioria, 
estrangeiros, consagrados na análise da temática, tendo em vista a incipiente pesquisa nacional atinente ao assunto. Dentre tais pesquisadores, ressalta-se Antonio Cassese, Allain Pellet, Henry Kissinger, Malcolm Shaw, David Raic, Nguyen Dinh, Patrick Daillier, Andrew Hurell e outros.

\section{A AUTODETERMINAÇÃO DOS POVOS NA ORDEM INTERNACIONAL}

As origens filosóficas da Autodeterminação dos Povos podem ser encontradas no trabalho de Pensadores iluministas como Jean-Jacques Rousseau. A Revolução Francesa, por exemplo, possuía em seu cerne estreita vinculação com as ideias político-filosóficas do "Contrato Social" de Jean-Jacques Rousseau, tendo por norte a manutenção da volontée générale como base para a proteção da ordem democrática, da liberdade individual e do exercício de autoridade legítima. Essas ideias atribuem ênfase na personalidade individual do ser humano e no direito quase ilimitado de autodeterminação do indivíduo (Rousseau, 2002).

A Revolução Francesa levou à derrubada da ordem social feudal e a profundas modificações da ordem política daquele período. A autoridade monárquica foi substituída pela doutrina da soberania. A Revolução construiu o dogma de que o governo deveria basear-se na vontade do povo e não na vontade de um rei. As instituições estabelecidas foram abolidas e substituídas pela representação direta do povo (Raic, 2002, p. 174; Teixeira, 2011, p. 88-119).

Formulações iniciais da autodeterminação, a partir de então expressam, em seu nível mais arcaico, o desejo humano fundado na dominação de seu próprio destino. Politicamente, o ideal foi invocado em nome de pessoas que desejavam deter a potência para governar-se a si mesmos, ou pelo menos preferir - no que diz 
respeito à sua nação - escolher seu próprio governo, a estar submetido a uma ordem política que não a sua. O princípio forneceu a ideologia e ímpeto para movimentos políticos que levaram à elaboração de documentos como a Declaração Francesa dos Direitos do Homem e do Cidadão e o Declaração de Independência Americana, e foi adaptado para o contexto de inúmeras lutas políticas desde então (Trinidad, 2018, p. 6-7).

No Século XX, embora existam registros políticos que contrapõem soviéticos e americanos como os precursores do ideário, seria impreciso e pretensioso prever o surgimento da autodeterminação como norma legal antes da Segunda Guerra Mundial. São exemplos retóricos a vertente proposta pelo Comandante Soviético Vladimir Ilich Lenin que defendia a autodeterminação como princípio anticolonialista e como reflexo da luta de classes (D'EnCAusse, 1971) ou ainda o Presidente Estadunidense Woodrow Wilson - academicamente muito defendida - que se materializou antes e durante a Primeira Guerra Mundial, no famoso discurso dos quatorze pontos que o sistema internacional deveria basear-se não no equilíbrio de poder e sim na autodeterminação ética (KIssinger, 2012, p. 3; Sterio, 2013, p. 9) com vistas a promover justiça a todos os povos e nacionalidades. Nenhuma das vertentes deram frutos em qualquer sentido operacional durante os anos entre guerras (CASSESSE, 1995, p. 14-25) não passando de mero discurso político.

O Pacto da Liga das Nações que inaugurou nova ordem internacional, silenciou sobre a autodeterminação (TrinidAD, 2018, p. 7) e embora até fosse ventilada, a ideologia de autodeterminação não foi verdadeiramente aceita perante o ambiente institucional internacional, sobretudo, por conta da plena vigência dos interesses colonialistas europeus, alardeados perante a Sociedade Internacional a partir da Conferência de Berlim de 1885 (Sterio, 2013, p. 89).

Foi somente com o fim da Segunda Guerra Mundial que o Princípio da Autodeterminação dos Povos, cunhado e instituído formalmente como um "propósito" da Organização das Nações Unidas 
- no art. $1^{\circ}$, parágrafo $2^{\circ}$ da Carta de $1945^{1}$ - e como um vetor da Cooperação Internacional Econômica e Social - Art. 55 da Carta $^{2}$ passou a fazer parte dos documentos internacionais.

A partir de sua verdadeira instituição na ordem internacional e da pacificação do entendimento de que se trataria de um princípio internacional, foi que a Autodeterminação dos Povos passou a adquirir cogência. Fato de importância ímpar para a sua consolidação foi a aprovação da Resolução 1514 de 15 de dezembro de 1960, durante a XV Assembleia Geral das Nações Unidas, em documento que passou a ser chamado como "Declaração Internacional sobre a Concessão de Independência aos Países e Povos Coloniais." (Organização das NaÇÕES UnidAs, 1960).

Nela, a Assembleia Geral declara que a sujeição dos povos a uma subjugação, dominação ou exploração constitui uma negação aos direitos humanos fundamentais, sendo contrária à Carta das Nações Unidas. Além disso, defende que todos os povos têm o direito de livre determinação e; em virtude desse direito, devem ter a prerrogativa inalienável de definir sua condição política e perseguir livremente seu desenvolvimento econômico, social e cultural (Assembleia Geral DAS NaÇÕES UnidAs, 1960).

Embora festejado por ter sido alçado ao patamar de "Direito Fundamental” em diversas resoluções da Assembleia Geral da ONU³

1 Artigo 1. Os propósitos das Nações unidas são: (...) Desenvolver relações amistosas entre as nações, baseadas no respeito ao princípio de igualdade de direitos e de autodeterminação dos povos, e tomar outras medidas apropriadas ao fortalecimento da paz universal.

2 Artigo 55. Com o fim de criar condições de estabilidade e bem estar, necessárias às relações pacíficas e amistosas entre as Nações, baseadas no respeito ao princípio da igualdade de direitos e da autodeterminação dos povos, as Nações Unidas favorecerão: a) níveis mais altos de vida, trabalho efetivo e condições de progresso e desenvolvimento econômico e social; b) a solução dos problemas internacionais econômicos, sociais, sanitários e conexos; a cooperação internacional, de caráter cultural e educacional; e c) o respeito universal e efetivo dos direitos humanos e das liberdades fundamentais para todos, sem distinção de raça, sexo, língua ou religião.

3 Dentre as quais, podemos citar 421 (V); 545 (VII); 637 (VII); 738 (VIII); 837 (IX); 1188 (XII); 1314 (XIII); 1514(XV); 1654 (XVI), 2200A (XXI); 2625 (XXV). 
e pelo Pacto Internacional sobre Direitos Econômicos, Sociais e Culturais $^{4}$; e ainda ter sido abordado como regra de jus cogens perante a própria Corte Internacional de Justiça (Lima, 2019, p. 283) o Princípio da Autodeterminação dos Povos pode ser visto como um "aglomerado de normas e conceitos ideológicos inter-relacionados" (Hurell, 2000, p. 200) que se espraia no campo normativo como uma norma jurídica que se traduz no exercício pleno de soberania (Dihn; Daillier; Pellet, 2003, p. 532; Accioly; Silva, 2008, p. 104) e como uma ideologia política que extrapola, por vezes, a origem legalista e jurídica de sua finalidade (BArATA, 2012, p. 96).

\section{AS OPINIÕES CONSULTIVAS COMO FONTES DE DIREITO INTERNACIONAL}

Uma vez que o presente escrito pretende analisar casos relativos à Autodeterminação dos Povos no corpo jurisprudencial da Corte Internacional de Justiça, verificou-se que não existem casos contenciosos que tenham abordado diretamente a temática, ao passo que, no exercício da jurisdição consultiva isso ocorreu em diversas ocasiões, que aqui serão abordadas.

A Carta das Nações Unidas incluiu a Corte Internacional de Justiça como parte de sua estrutura através do art. $7^{\circ}$ e instituiu formalmente a sua existência em seu art. 92 fazendo constar que esta será

\footnotetext{
4 ARTIGO $1^{\circ}$. 1 . Todos os povos têm direito a autodeterminação. Em virtude desse direito, determinam livremente seu estatuto político e asseguram livremente seu desenvolvimento econômico, social e cultural. 2. Para a consecução de seus objetivos, todos os povos podem dispor livremente de suas riquezas e de seus recursos naturais, sem prejuízo das obrigações decorrentes da cooperação econômica internacional, baseada no princípio do proveito mútuo, e do Direito Internacional. Em caso algum, poderá um povo ser privado de seus próprios meios de subsistência. 3. Os Estados Partes do Presente Pacto, inclusive aqueles que tenham a responsabilidade de administrar territórios não-autônomos e territórios sob tutela, deverão promover o exercício do direito à autodeterminação e respeitar esse direito, em conformidade com as disposições da Carta das Nações Unidas.
} 
o principal órgão judiciário dentre sua organização. Malcolm Shaw (2012, p. 798) citando o ex-juiz da Corte Manfred Lachs afirma que ela seria "a guardiã da legalidade para a comunidade internacional como um todo" mesmo que seja inevitável que assuntos de natureza política se entrelacem com as questões jurídicas.

Assim, são considerados sob sua jurisdição todos aqueles Estados que adiram à Carta, tendo em vista que esta possui como anexo o estatuto de funcionamento da Corte. Fica estabelecido na Carta também que além dos litígios propriamente ditos, a Corte poderá atuar, por força do artigo 96, sempre a pedido da Assembleia Geral ou o Conselho de Segurança, através da confecção de opinião consultiva. Estabelecendo, portanto, além da competência contenciosa, outra de natureza consultiva (OrganizaÇão das NaÇõEs Unidas, 1945).

No Estatuto da Corte, anexo à Carta, o Capítulo IV se ocupa da espécie jurisdicional dos Pareceres ou Opiniões Consultivas. O art. 65 do Estatuto estabelece que a Corte "poderá dar parecer consultivo sobre qualquer questão jurídica a pedido do órgão que, de acordo com a Carta das Nações Unidas ou por ela autorizado, estiver em condições de fazer tal pedido" (OrganizaÇão das NaÇÕES UNIDAS, 1945). Importante frisar também, algo que foi sendo construído ao longo do exercício da função consultiva, embora isso nunca tenha ocorrido, que ela pode se recusar a dar um parecer se considerar que não é conveniente proferi-lo, ainda que, não tenha se abstido até o momento (Mello, 2000, p. 653; Lima, 2019, p. 285).

Diferentemente do que se pressupõe a respeito dos casos contenciosos, a jurisdição consultiva da Corte não visa resolver - pelo menos não diretamente - as disputas entre estados, mas sim disponibilizar pareceres jurídicos a órgãos e instituições que os solicitem. Desta forma, embora não resolvam os casos concretos, elas servem como munício argumentativo na construção de um discurso de legitimidade internacional para os casos relativos à autodeterminação dos povos.

Neste sentido, ainda que o conteúdo das Opiniões Consultivas sejam classificados como soft norm e não disponham do caráter 
vinculante, caracterizado pela obrigatoriedade, inquestionabilidade e oponibilidade erga omnes, (SouzA, 2011, p. 1192) é de se concluir, que elas "possuem um grau de cogência relativo" (SOAREs, 2002, p. 136) e há de se considerar que, no Direito Internacional a exigibilidade de uma norma repousa sobre o compromisso assumido pelo Estado. Assim, para acomodar as diferentes vontades em se engajar às normas, $\mathrm{o}$ Direito Internacional alberga a ideia de diferentes graus de normatividade (Varella, 2009, p. 61). Assim, cada parecer contém uma conduta a ser seguida [...] e, com ela, uma obrigatoriedade implícita. Tal noção é capaz de expressar o mais genuíno jogo das relações internacionais, no qual o acatamento e execução do conteúdo de pareceres por parte dos Estados refletem [...] obrigações morais, mas também questões de viés político, moral e, principalmente, jurídico (Souza, 2011, p. 1193; Shaw, 2012, p. 798).

Após exposto o Princípio da Autodeterminação dos Povos e em vista da análise jurisprudencial proposta neste escrito, analisada a jurisdição consultiva da Corte Internacional de Justiça que constitui a única modalidade jurisdicional sob a qual a Corte se manifestou sobre a temática, passamos aos casos.

\section{A OPINIÃO CONSULTIVA SOBRE 0 ESTATUTO INTERNACIONAL DO SUDOESTE AFRICANO}

O primeiro caso abordado trata objetivamente de questões que abrangem o status internacional da "África do Sudoeste" (International Status of South-West África). O território onde atualmente está situada a República da Namíbia.

Desde 1915, o território da África do Sudoeste foi ocupado pela União da África do Sul, que à época estava sob domínio britânico. Em 1920, a Liga das Nações submeteu o território da África do Sudoeste ao "regime de tutela" como sendo um protetorado sul-africano, que o agregou ao seu território como sua quinta região nacional de 
facto (Ziemann, s/d; Oakes, 1995). Após o fim da Segunda Guerra Mundial a União da África do Sul, alegando que o mandato de tutela terminara, solicitou o reconhecimento, por parte da Organização das Nações Unidas, da anexação do território à União. As Nações Unidas se recusaram em emitir juízo de valor sobre a eventual incorporação, em virtude da não manifestação do povo autóctone do território sobre o tema e convidou a União da África do Sul a submeter novamente o território ao regime de tutela previsto no Capítulo XII da Carta da ONU. Seria necessário que o povo submetido ao regime colonial decidisse o status jurídico a que gostaria de se submeter.

A União se recusou em aceitar tal recomendação, fato que culminou na submissão, por parte da Assembleia Geral das Nações Unidas, de algumas questões de ordem jurídica sobre o status daquele território à Corte Internacional de Justiça. Solicitou-se à Corte: Qual seria o status internacional do território da África do Sudoeste e quais são as obrigações internacionais da União da África do Sul decorrentes deste fato, e em particular: a) a União da África do Sul continua a ter obrigações internacionais em virtude do mandato para o Sudoeste Africano, e se assim for, quais são essas obrigações?; b) São as disposições do Capítulo XII da Carta aplicáveis ao território do Sudoeste Africano, e se o forem, de qual modo?, e; c) Tem a União da África do Sul competência para determinar e modificar a situação internacional do território do Sudoeste Africano, ou, em caso de uma resposta negativa, quem tem competência para determinar e modificar o estatuto internacional do território? (Corte InTERnacional de Justiça, 1950, p. 7)

Em relação ao questionamento especial "a”, a Corte, que emitiu seu parecer em 11 de julho de 1950, entendeu que o fato da Liga das Nações haver deixado de existir não desonera a União da África do Sul das responsabilidades assumidas no plano internacional. Em alusão ao artigo 80 , parágrafo $1^{\circ}$ da $\operatorname{Carta}^{5}$ que ressalva e resguarda

\footnotetext{
Artigo 80. 1. Salvo o que for estabelecido em acordos individuais de tutela, feitos de
} conformidade com os Artigos 77, 79 e 81, pelos quais se coloque cada território sob 
as obrigações e as prerrogativas de direito dos territórios submetidos ao regime de tutela. Assim sendo, sedimentou a Corte que as obrigações assumidas pela União continuavam em relação ao território em questão. Sobre o aspecto das obrigações que derivariam da continuidade obrigacional de tutela, estariam: 1) o dever de administrar o território, tal seria reflexo do 'dever sagrado' de civilização, e; 2) o dever de manutenção, submetido ao regime de supervisão da "liga", transmitido posteriormente à Assembleia Geral das Nações Unidas (Corte Internacional de Justiça, 1950, p. 7-14).

Sobre o questionamento "b", a Corte decidiu que o Capítulo XII da Carta era aplicável ao território da África do Sudoeste e o modo seria através do disposto na própria Carta no que alude ao Sistema Internacional de Tutela existente no referido Capítulo (CORTE INTERNACIONAL DE JUSTIÇA, 1950, p.14-16).

No que respeita a possibilidade de a União modificar unilateralmente o status legal do território, a Corte declarou expressamente sua impossibilidade. Em alusão ao que seria 'normal' para a modificação do status de um território como o do caso em tela, seria a via da submissão ao regime de tutela, através de um acordo proposto e aceito por ambas as partes, sem qualquer indício de vício de consentimento e, posteriormente, aprovado pela própria Assembleia Geral da ONU (Corte Internacional de JustiçA, 1950, p. 17-19).

Alguns anos mais tarde, em 1956 e 1962, após a Corte Internacional de Justiça ter, através da Opinião Consultiva de 1950, solidificado o entendimento de que o capítulo da Carta das Nações Unidas relativo ao Sistema Internacional de Tutela deveria continuar sendo aplicado ao caso e mantido sob fiscalização da Assembleia Geral, nos mesmos moldes do que se realizava sob os auspícios da ordem jurídica

este sistema e até que tais acordos tenham sido concluídos, nada neste Capítulo será interpretado como alteração de qualquer espécie nos direitos de qualquer Estado ou povo ou dos termos dos atos internacionais vigentes em que os Membros das Nações Unidas forem partes. 
da Sociedade das Nações e que tais observações se aplicam, particularmente, no que atine aos informes anuais e petições, porventura realizados (Corte Internacional de JustiçA, 1955, p. 56), foram interpostas duas outras solicitações de Opiniões Consultivas, tanto pela Assembleia Geral quanto por estados, que abordaram questões práticas relacionadas à possibilidade da Comissão de Fiscalização do sistema de mandato do território do Sudoeste Africano participar de audiência (Admissibilidade de Solicitações de Audiência pela Comissão da África do Sudoeste, emitida em $1^{\circ}$ de junho de 1956) (Corte Internacional de JustiçA, 1956) e outra que questionava a continuação do mandato relativo a África do Sudoeste e os deveres e comportamentos da África do Sul como potência, solicitados pelos governos da República da Etiópia e da Libéria (Casos Relativos ao Sudoeste Africano - Exceções Preliminares, emitida em 21 de dezembro de 1966) (Corte Internacional de Justiça, 1962). Importante salientar que a União Sul-africana deixou de existir a partir de 31 de março de 1961, transformando-se formalmente na República da África do Sul (OAkes, 1995).

Em virtude das insistentes negativas de retirada e da inflexão a um mandato internacional viável, composto por condições efetivas de fiscalização e informação bem como do bem-estar da população em questão, a Assembleia Geral das Nações Unidas, através da Resolução 2145 (XXI), declarou terminado o Mandato territorial da União Sul-africana sobre o território da África do Sudoeste, afirmando que a potência não possuía nenhum direito sobre o território até então administrado (Assembleia Geral das Nações Unidas, 1966). Posteriormente, após a manifestação da Assembleia Geral, o Conselho de Segurança das Nações Unidas, através da Resolução 276 (1970) também declarou que a eventual continuação da presença sul-africana naquele protetorado era ilegal (Conselho de Segurança das Nações UNIDAS, 1970).

O Conselho de Segurança, por sua vez solicitou à Corte a elaboração de nova Opinião Consultiva, diante do reconhecimento 
da ilegalidade das ações da África do Sul perante o território do Sudoeste Africano. O fez através dos seguintes questionamentos: Quais são as consequências jurídicas produzidas aos Estados da continuação da presença da África do Sul na Namíbia, inobstante o disposto na Resolução 276 (1970) do Conselho de Segurança das Nações Unidas? Que caso fosse admitida a questão e opinado pela ratificação da ilegalidade, a Corte deveria opinar se a África do Sul teria a obrigação de retirar imediatamente sua administração do território namíbio e deixar de ocupar aquele território; e ainda, no que diz respeito aos demais estados membros das Nações Unidas, se eles teriam a obrigação de reconhecer a ilegalidade da presença daquela potência na Namíbia e de reconhecer a falta de validade das medidas adotadas por aquela em nome do seu ex-protetorado, além de abster-se de todo ato, em particular, de toda a relação com o governo sul-africano que implique no reconhecimento da legalidade de sua presença e dessa administração ou que constitua auxílio ou assistência nesse respeito. Por fim, ainda, uma terceira solicitação, no que diz respeito aos estados que não são membros das Nações Unidas, abster-se de prestar assistência, dentro dos limites do questionamento anterior no que respeita a Namíbia (Corte Internacional de Justiça, 1971).

A Corte Internacional de Justiça, emitiu então o parecer em data de 21 de junho de 1971, na Opinião nominada de "Consequências Jurídicas existentes para os Estados da continuação da presença da África do Sul na Namíbia (África do Sudoeste), tendo em vista o disposto na Resolução 276 (1970) do Conselho de Segurança”. Nela, a Corte afirmou que a ONU poderia unilateralmente, ainda que não esteja expresso no texto, terminar tratado bilateral que atribui efeitos jurídicos a mandato de proteção. Que isso teria validez, inclusive, para obrigações iniciadas durante a vigência da Sociedade das Nações, tendo em conta que as Nações Unidas são as legítimas sucessoras daquela. Ainda, que embora a Assembleia Geral não possuísse em suas competências a declarar findado a tutela sul-africana sobre a Namíbia com valor determinativo ou finalidade operativa, a resolução lá emitida 
instou o Conselho de Segurança a se manifestar, por ser competente em virtude do artigo 24 da Carta das Nações Unidas. O Conselho de Segurança pôde então realizar tal declaração de ilegalidade como decorrência de sua responsabilidade para a manutenção da paz e da segurança internacional (Corte Internacional de JustiçA, 1971).

Assim, no mérito, decidiu a Corte que os estados membros estariam obrigados a abster-se de estabelecer relações convencionais com a África do Sul em todos os casos em que o governo daquele país pretendesse atuar em nome da Namíbia. No mesmo sentido, os estados membros estariam obrigados a abster-se de enviar missões diplomáticas à União Sul-africana que incluíssem em sua jurisdição o território namíbio; além da obrigação de abstenção relativa ao estabelecimento de relações econômicas ou de qualquer outra índole com a África do Sul em nome ou com possíveis eventuais relações com o território namíbio que pudessem reforçar a autoridade daquela sobre dito território. Todas as razões vinculariam também os estados não membros das Nações Unidas (Corte Internacional de Justiça, 1971).

Após toda a manifestação dos órgãos da Organização das Nações Unidas e sobretudo, da emissão de diversas opiniões consultivas sobre o inalienável direito à autodeterminação do povo namíbio, o respaldo jurídico demonstrativo da ilegalidade a que estava submetido aquele povo serviu de base para a construção e materialização posterior da independência da Namíbia.

À guisa de conclusão preliminar, ao referir-se ao caso de 1950, pode-se afirmar que o contexto em que foi emitida a Opinião Consultiva sobre o Sudoeste Africano, era ainda pendente de consagração do princípio da autodeterminação dos povos, com o alcance e importância com que o conhecemos hoje. De qualquer forma, as referidas decisões erigiram frente à normativa internacional a defesa da plenitude dos modos de autodeterminar-se. A capacidade de decisão de insurgir-se, declarar-se, crer-se independente depende unicamente da comunidade de indivíduos a se determinar e isso deve ser feito com base nos regimes legais sob o Sistema Internacional de Tutela. A atuação da 
comunidade internacional deriva deste ideário levantado em prol da libertação dos povos coloniais, servindo de motriz para os processos de autodeterminação.

A União e, posteriormente, a própria República Sul Africana continuou ocupando o Sudoeste Africano ate 1989, quando por fim, a República da Namíbia tornou-se independente.

Assim, pode-se concluir que ao prolatar as Opiniões Consultivas sobre o Sudoeste Africano a Corte demonstrou apego à legalidade internacional, sobretudo ao Sistema Internacional de Tutela, quer seja o da Sociedade das Nações ou o do Capítulo XIII da Carta das Nações Unidas, que serviram como base à manutenção do status de pendência da autodeterminação da Namíbia. O legalismo levantado demonstra o processo de sedimentação paulatina dos conceitos que alicerçam a prática jurídica e política da autodeterminação dos povos.

\section{A OPINIÃO CONSULTIVA SOBRE O SAARA OCIDENTAL}

A segunda Opinião Consultiva que aborda a questão da autodeterminação dos povos é a que versa sobre o Saara Ocidental. Resultado de um processo de descolonização mal conduzido pela Espanha - que se retirou de seu território colonial, até então conhecido como "Sáhara Español” em 1975, o Saara Ocidental, foi invadido e ocupado pelo Reino do Marrocos e pela Mauritânia que acreditavam possuir laços étnicos e culturais com o povo que ali habitava (SMOLAREK, 2013, p. 34-38).

Dado o anseio de ocupação demonstrado pelo Marrocos e pela Mauritânia, ignorando o anseio de autodeterminação da população local, ambos os países requisitaram durante a Assembleia Geral da ONU de 1974 à Corte Internacional de Justiça a confecção de uma Opinião Consultiva sobre as seguintes questões: 1) se era o Saara Ocidental, ao tempo da colonização espanhola, terra nullius; e caso a primeira questão fosse negativa; 2) Quais eram os liames vinculativos 
entre o território do Saara Ocidental, o Marrocos e a Mauritânia (Corte Internacional de Justiça, 1975).

Para a instrução do parecer consultivo da Corte, a Espanha disponibilizou enorme quantidade de documentos, mapas, e informações, comprovando solidamente a sua vinculação jurídica ao território. $\mathrm{O}$ reino do Marrocos, por sua parte, contratou uma série de juristas franceses de grande renome para contestar e desenvolver a exposição escrita de sua pretensão. A Mauritânia contratou um jurista belga para que este justificasse sua vinculação (Miguel, 1995, p. 94).

Em 16 de outubro do ano de 1975, a Corte Internacional de Justiça torna público o parecer consultivo das questões levantadas. Com relação ao primeiro questionamento, de que o Saara Ocidental se tratava de terra nullius quando da chegada dos espanhóis, a Corte manifestou-se contrariamente. De acordo com o documento, a vinculação territorial espanhola remonta ao ano de 1884, quando, por Decreto Real, o governo espanhol considerou estar o território do Saara Ocidental - então chamado de Río de Oro - sob sua proteção. Ainda, levando em conta o conceito de terra nullius como sendo determinada parte do planeta que não detenha nenhum tipo de população permanente e organizada política e socialmente. Não era o caso do Saara Ocidental que mesmo não estando sob a égide de um Estado, antes da ocupação espanhola, possuía tribos organizadas política e socialmente, logo, não poderia tratar-se de terra de ninguém (CORTE InTERNACIONAL DE JustiçA, 1975).

Uma vez respondida negativamente a primeira questão, a Corte deveria elucidar o tangível à segunda pergunta formulada: quais seriam os liames jurídicos entre o território do Saara Ocidental e o Reino do Marrocos e entre o primeiro e a entidade Mauritana.

$\mathrm{Na}$ primeira parte da pergunta, a Corte rechaçou a possibilidade de, à luz da Resolução da Assembleia Geral que solicitou sua atuação - que nasceu embebida no anseio de descolonização e autodeterminação -, analisar tão-somente as vinculações de natureza territorial, sem abranger o elemento pessoal do Saara Ocidental, principalmente dado 
o sabido anseio de anexação do território pelo Marrocos e Mauritânia (Corte Internacional de Justiça, 1975).

Para a Corte, a configuração dos laços de soberania e autoridade necessitaria por parte do país requerente, do exercício de dois elementos precípuos, sendo eles: a) a intenção de assenhorear-se exteriorizando a vontade de agir como soberano; e b) efetivar o exercício real ou "de exibição" de autoridade. Nenhum destes fora exercitado pela administração marroquina em períodos anteriores.

O que se levou em consideração no parecer foi que, dadas as características nômades do povo berbere que habitava o Saara Ocidental, o Marrocos logrou comprovar somente que uma minoria tribal saaraui constituía núcleos ao norte do território submetia-se aos sultões marroquinos. Por se tratar de pequena fração populacional, restou impossibilitada a procedência da tese de existência de ligações de soberania entre ambas as unidades territoriais. Assevera, nesse sentido, o parecer da Corte Internacional de Justiça (1975, p. 41):

Thus, even taking account of the specific structure of the Sherifian State, the material so far examined does not establish any tie of territorial sovereignty between Western Sahara and that State. It does not show that Morocco displayed effective and exclusive State activity in Western Sahara. It does however provide indications that a legal tie of allegiance had existed at the relevant period between the Sultan and some, but only some, of the nomadic peoples of the territory.

Sobre as tribos submetidas ao reino marroquino, bem como sua representatividade, aduz Francisco Villar apud Miguel (1995, p. 96):

Por lo demás, es importante hacer notar que esas "ciertas, pero sólo ciertas poblaciones nómadas sobre el territorio" que se hallaban en "sumisión" al sultán marroquí son los nómadas tekna que, en la actualidad, representan a lo sumo un $20 \%$ de la población total del territorio y que, además, no se sometían directamente al sultán, sino indirectamente, al estar sometidas a los caídes de los tekna sedentarios del Nún y del Draa. 
Depreende-se do material documental analisado que, a única procedência lograda pelo Marrocos e pela Mauritânia (conforme supramencionado sobre o Marrocos e adiante exposto sobre a Mauritânia) nesta lide, fora o reconhecimento das ligações étnicas que se observaram nas regiões fronteiriças, graças ao nomadismo típico.

É de se ressaltar a inserção crítica e lógica levantada por Mauro Santayana (1987, p. 58-59) sobre essas ligações étnicas fronteiriças: "Ora, tais laços existem em todas as fronteiras povoadas do mundo." Não se observaram, portanto, liames de soberania, e sim, meras ligações populacionais.

Sobre a existência de vínculos jurídicos entre o Saara Ocidental e a Mauritânia expôs a Corte que, "embora ambos compartilhem de numerosos vínculos raciais, linguísticos, religiosos e culturais, os dados apresentados para análise possibilitaram a conclusão de que as tribos eram independentes e inexistia qualquer instituição ou órgão que lhes fosse comum” (Corte Internacional de Justiça, 1975).

Diante do exposto, não se pôde considerar que as tribos tivessem uma "unidade" ou "entidade" capaz de ser beneficiária de obrigações, às quais incluíssem seus membros de forma comum. Tal fato torna incomprovado qualquer laço de soberania entre aqueles territórios, conforme traz em seu texto o parecer consultivo (CORTE INTERnACiONAL DE JustiçA, 1975, p. 56):

In the light of the above considerations, the Court must conclude that at the time of colonization by Spain there did not exist between the territory of Western Sahara and the Mauritanian entity any tie of sovereignty, or of allegiance of tribes, or of "simple inclusion" in the same legal entity.

Por fim, em sua conclusão, o parecer desautoriza expressamente a postura marroquina e mauritana de assenhorear-se do território saaraui. Esclarece o parecer que, “[...] as conclusões logradas pelo tribunal sobre a natureza dos vínculos jurídicos relativos entre o território [Saara Ocidental] com o Reino do Marrocos e com a "entidade" Mauritana 
diferem materialmente das opiniões emitidas pelo Marrocos e pela Mauritânia. Na opinião do tribunal, esses vínculos jurídicos não implicam nem em soberania territorial, nem em co-soberania, nem em inclusão territorial numa entidade jurídica." (CORTE INTERNACIONAL DE JustiçA, 1975).

Não obstante, a Corte declara que o requerimento de opinião consultiva feita na Assembleia Geral das Nações Unidas, pelo Marrocos e pela Mauritânia, não afetava nem modificava o direito de autodeterminação da população saaraui. Ainda - reforça o parecer -, que a opinião da Corte Internacional de Justiça foi requerida "particularmente" para auxiliar a Assembleia Geral das Nações Unidas a emitir um posicionamento oficial sobre as pretensões marroquino-mauritanas.

De acordo com parecer (1975, p. 59-60), in verbis:

As already indicated in paragraph 70 of this Opinion, the General Assembly has made it clear, in resolution 3292 (XXIX), that the right of the population of Western Sahara to self-determination is not prejudiced or affected by the present request for an advisory opinion, nor by any other provision contained in that resolution. [...] In framing its answer, the Court cannot be unmindful of the purpose for which its opinion is sought. Its answer is requested in order to assist the General Assembly to determine its future decolonization policy and in particular to pronounce on the claims of Morocco and Mauritania to have had legal ties with Western Sahara involving the territorial integrity of their respective countries.

Com essa Opinião Consultiva a Corte estabelece o fundamento de um Direito Internacional no que diz respeito à autodeterminação dos povos até aquele momento (Drew, 2009, p. 87).

Em tempo, o Saara Ocidental, a despeito de haver fundado a República Árabe Saaraui Democrática, não logrou autodeterminar-se plenamente ante a anexação marroquina de parte de seu território. O Marrocos inclusive construiu um muro de areia 
cercado por minas terrestres ao longo de uma extensão de mais de 2.500 quilômetros, dividindo o território livre, onde está instalada a República Árabe Saaraui Democrática, do território ocupado e espoliado. De acordo com a ONU, o território do Saara Ocidental segue pendente de descolonização e o seu inalienável direito à autodeterminação segue resguardado, imanente, dependendo apenas das circunstâncias políticas que cercam o Princípio da Autodeterminação costurarem as condições necessárias à sua concretização (Smolarek, 2013, p. 34 -38).

Diante da pendência da descolonização cuja principal responsável, nos termos da Carta das Nações Unidas, continua sendo a Espanha, que é a possuidora legítima do mandato de tutela, a Corte examina um ponto de ruptura de grande importância que seria a alegação da Espanha de que nem o Marrocos e nem a Mauritânia teriam legitimidade de solicitar na Assembleia Geral um parecer consultivo para a Corte, tendo em vista que essas não estariam diretamente envolvidas na questão da descolonização pendente. Assim, a Corte defendeu na Opinião Consultiva que a disputa que originou a petição da opinião se deu no âmbito dos procedimentos de descolonização levados a cabo pela Assembleia Geral e cujo anseio, que gerou a solicitação do parecer, serviria para agregar a opinião que ajudasse aquele órgão a descolonizar o território e não propriamente imiscuir-se no eventual conflito existente entre as partes solicitantes (CORTE INTERNACIONAL DE Justiça, 1975; Shaw, 2012, p. 826).

Desta forma, fica evidenciado que a Corte, ao realizar uma análise referente aos liames étnico-políticos do povo que habita o Saara Ocidental e ainda, desestimando a pretensão anexionista marroquino-mauritana daquele território, demonstra uma posição materialista. Equivale a dizer que o percurso adotado pela Corte transcende o aspecto legalista mencionado na Opinião sobre o Sudoeste Africano - com o aspecto da descolonização aqui, ainda pendente - atingindo diretamente o direito de autodeterminação ao desestimar qualquer atentado ou vilipêndio à pretensão do povo saaraui. 


\section{CONCLUSÃO}

A legitimidade é um aspecto primordial à materialização da justiça. Esta, por sua vez, constitui meio para o destemor justo das nações oprimidas. Significa dizer, alusivamente que, o direito de autodeterminação constitui, legitimamente, uma luta justa. Contudo, legitimidade e justiça não significam que a realidade política seja ou venha a ser alterada. Essa dualidade fica bem demonstrada com a abordagem do Princípio da Autodeterminação frente aos casos aqui realizada.

Embora os discursos políticos tenham dado lugar a um arcabouço jurídico de viés internacional e mesmo que já se tenham transcorrido mais de um século do início das lutas dos movimentos independentistas, ainda existem territórios no globo submetidos ao poder colonial. $\mathrm{O}$ Princípio da Autodeterminação dos Povos constituiu e ainda constitui poderoso argumento para a descolonização, para a libertação nacional e para a emancipação dos indivíduos enquanto componentes de povos submetidos a estados nacionais na pura conotação da autodeterminação como desejo de autonomia sobre seu próprio destino.

A Corte Internacional de Justiça como guardiã da legalidade e da legitimidade da Sociedade Internacional tocou em temas sensíveis relacionados a autodeterminação, conforme vimos. Embora não tenham influenciado politicamente na resolução dos casos - tendo em vista que sua natureza jurisdicional, apesar de tangenciar o político, não se confunde com esse -, lograram legitimar a condução dos processos descolonizatórios, auxiliando na construção de uma Sociedade Internacional plural mais justa e equânime, produzindo nações livres, soberanas e pacíficas, conforme verificamos no Caso da República da Namíbia.

Em outro caso, a emissão de sua opinião consultiva constitui evidente registro da ilegalidade das ocupações que são legitimadas pelo poder político e financeiro, mantendo o jugo e a espoliação vigentes em pleno Século XXI, como no Caso do Saara Ocidental. 
Assim, verificamos que até o presente momento, a partir dos casos já analisados por aquele tribunal, existem dois motes principais aos que poderíamos nos apegar para definir um padrão ou percurso hermenêutico das referidas manifestações. Por um lado, uma exegese legalista, que leva em conta a estrita observância daquilo já se materializou ao longo do tempo na Sociedade Internacional, como por exemplo, no Caso do Sudoeste Africano através da contundente defesa do Capítulo XII da Carta das Nações Unidas que estatui o Sistema Internacional de Tutela como eixo central, ao aportar lição elementar da paulatina construção dos conceitos que alicerçam a prática jurídica e política da autodeterminação dos povos.

Por outro lado, uma posição materialista, quando a Corte realiza uma análise referente aos liames étnico-políticos do povo do Saara Ocidental. Aqui, os reflexos transcendem a legalidade internacional e abordam indiretamente temas relacionados ao processo de descolonização daquele povo e território, ao desestimar qualquer atentado ou vilipêndio ao inalienável e legítimo direito de autodeterminação do povo saaraui, ainda que, por circunstâncias políticas, não tenham ainda conseguido alcançar a materialização do seu direito.

A eficácia das Opiniões não está aqui posta à prova, mas sim, são aventados indícios hermenêuticos de dissociação da postura da Corte nos dois casos inerentes ao tema. Trata-se de uma busca por legitimação e justiça. Pelo direito das nações a gerir o seu próprio destino.

\section{REFERÊNCIAS}

ACCIOLY, Hildebrando. SILVA, Geraldo Eulálio do Nascimento e. Manual de Direito Internacional Público. São Paulo: Saraiva. 1998.

ASSEMBLEIA GERAL DAS NAÇÕES UNIDAS. Resolução 2145 (XXI) de 27 de outubro de 1966. Disponível em: https://undocs.org/es/A/ RES/2145(XXI). Acesso em: 25 mar. 2021. 
ASSEMBLEIA GERAL DAS NAÇÕES UNIDAS. Resolução 1514 (XV) de 14 de dezembro de 1960. Disponível em https://undocs.org/es/A/ RES/1514(XV). Acesso em: 25 mar. 2021.

ASSEMBLEIA GERAL DAS NAÇÕES UNIDAS. Resolução da Assembleia Geral 1541 (XV) de 15 de dezembro de 1960. Disponível em https://undocs.org/es/A/RES/1541(XV). Acesso em: 25 mar. 2021.

BARATA, Maria João Ribeiro Curado. Nações Unidas e Resolução de Conflitos: Uma análise do Caso do Saara Ocidental. Relações Internacionais. Coimbra. Disponível em http://www.ces.uc.pt/myces/UserFiles/livros/1097_Barata\%202008\%20ONU\%20e\%20Resolu\%E7\%E3o\%20do\%20 Conflitos\%20-\%20O\%20Caso\%20do\%20SO.pdf. Acesso em: 25 mar. 2021.

CASSESE, Antonio., Self-Determination of Peoples: A Legal Reappraisal. Cambridge: Cambridge University Press, 1995.

CONSELHO DE SEGURANÇA DAS NAÇÕES UNIDAS. Resolução 276 de 30 de janeiro de 1970. Disponível em: https://undocs.org/es/S/ RES/276\%20(1970). Acesso em: 25 mar. 2021.

CORTE INTERNACIONAL DE JUSTIÇA. International Status of South-west Africa. Advisory Opinion. 1950. Disponível em: https://www. icj-cij.org/public/files/case-related/10/010-19500711-ADV-01-00-EN.pdf. Acesso em: 25 mar. 2021.

CORTE INTERNACIONAL DE JUSTIÇA. Admissibility of Hearings of Petitioners by the Committee on South West Africa. 1956. Disponível em: https://www.icj-cij.org/public/files/case-related/31/031-19560601-ADV-01-00-EN.pdf. Acesso em: 25 mar. 2021.

CORTE INTERNACIONAL DE JUSTIÇA. South West Africa (Ethiopia v. South Africa). 1962. Disponível em: https://www.icj-cij.org/public/ files/case-related/46/046-19621221-JUD-01-00-EN.pdf. Acesso em: 25 mar. 2021.

CORTE INTERNACIONAL DE JUSTIÇA. South West Africa (Liberia v. South Africa). 1962. Disponível em https://www.icj-cij.org/public/ files/case-related/47/047-19621221-JUD-01-00-EN.pdf. Acesso em: 25 mar. 2021.

CORTE INTERNACIONAL DE JUSTIÇA. Legal Consequences for States of the Continued Presence of South Africa in Namibia (South 
West Africa) notwithstanding Security Council Resolution 276 (1970). 1971. Disponível em: https://www.icj-cij.org/public/files/case-related/53/ 053-19710621-ADV-01-00-EN.pdf. Acesso em: 25 mar. 2021.

CORTE INTERNACIONAL DE JUSTIÇA. Western Sahara. Advisory Opinion. 1975. Disponível em: https://www.icj-cij.org/public/files/case-related/61/061-19751016-ADV-01-00-EN.pdf. Acesso em: 25 mar. 2021.

D'ENCAUSSE, Hélène Carrière. Unité prolétarienne et diversité nationale. Lénine et la théorie de l'autodétermination. In Revue française de science politique. n. 21 v.2. 1971. Disponível em: https://www.persee.fr/ doc/rfsp_0035-2950_1971_num_21_2_418048: Acesso em : 25 mar. 2021. DINH, NGUYEN; DAILLIER, Patrick; PELLET, Allain. Direito Internacional Público. 2.ed. Lisboa: Fundação Calouste Gulbenkian. 2003.

DREW, Catriona. Ce que l'autodetermination veut dire: The Stealing of The Western Sahara revisité. In.: CHAPAUX, Vincent; ARTS, Karin; LEITE, Pedro Pinto. Le Droit International et la question du Sahara Occidental. Leiden: IPJET. 2009.

FREITAS FILHO, Roberto; LIMA, Thalita Moraes. Metodologia de Análise de Decisões - MAD. In: Universitas Jus. n. 21, p. 1-17, jul./dez. 2010 Disponível em https://www.publicacoesacademicas.uniceub.br/jus/ article/view/1206. Acesso em: 25 mar. 2021.

HURELL, Andrew. International Law and the Changing Constitution of International Society. In: BYERS, M. (ed). The Role of Law in International Politics: Essays in International Relations and International Law. Oxford. Oxford University Press. 2000.

KISSINGER, Henry. Diplomacia. São Paulo: Saraiva. 2012.

LAKATOS, Eva Maria. Fundamentos de Metodologia Científica. São Paulo: Atlas, 2003.

LIMA, Lucas Carlos. A Opinião sobre o Arquipélago de Chagos: a jurisdição consultiva da Corte Internacional de Justiça e a noção de Controvérsia. In: Rev. Fac. Direito UFMG, Belo Horizonte, n. 75, pp. 281-302, jul./ dez. 2019. Disponível em https://revista.direito.ufmg.br/index.php/revista/ article/view/2039. Acesso em: 25 mar. 2021.

MELLO, Celso Duvivier de Albuquerque Mello. Curso de Direito Internacional Público. Rio de Janeiro: Renovar, 2000. 
MIGUEL, Carlos Ruiz. El Sahara Occidental y Espanha: Historia, Política y Derecho. Analisis Crítico de La Política Exterior Española. 1a ed. Madrid: Dykinson. 1995.

OAKES, Dougie. Illustrated History of South Africa: The Real Story. Londres: Reader's Digest, 1995.

ORGANIZAÇÃO DAS NAÇÕES UNIDAS. Carta das Nações Unidas e Estatuto da Corte Internacional de Justiça. 1945. Disponível em: https:// www.un.org/en/about-us/un-charter. Acesso em: 25 mar. 2021.

ORGANIZAÇÃO DAS NAÇÕES UNIDAS. International Covenant on Economic, Social and Cultural Rights. 1960. Disponível em: https:// treaties.un.org/doc/Publication/UNTS/Volume\%20993/volume-993-I-14531-English.pdf. Acesso em: 25 mar. 2021.

RAIC, David. Statehood and the International Law of Self-Determination. Hague: Kluwer Law International, 2002.

ROUSSEAU, Jean-Jacques. Do Contrato Social. Editora Ridendo Castigat Mores. Trad. De Rolando Roque da Silva. 2002.

SANTAYANA, Mauro. Dossiê da Guerra do Saara. Rio de Janeiro: Paz e Terra, 1987.

SHAW, Malcolm. Direito Internacional. São Paulo: Martins Fontes, 2010.

SMOLAREK, Adriano Alberto. Conflito no Saara Ocidental: Um país além da miragem. Conjuntura Global, Curitiba, Vol.2, n.1, jan./mar., 2013. Disponível em: https://revistas.ufpr.br/conjgloblal/article/view/34661/21499 acesso em 25 de março de 2021.

SOARES, Guido. Curso de Direito Internacional Público. São Paulo: Atlas, 2002.

SOUZA, Mayra do Amaral Gurgel Alves de. A Corte Internacional de Justiça e sua Função Consultiva. Anais do $9^{\circ}$ Congresso Brasileiro de Direito Internacional. et.al., Brasília: Versão oficial CD-ROM, 2011.

STERIO, Milena. The Right to Self-Determination Under International Law: "Selfistans", secession, and the rule of the great powers. New York: Routledge, 2013.

TEIXEIRA, Anderson Vichinkeski. Teoria Pluriversalista do Direito Internacional. São Paulo: Editora WMF Martins Fontes, 2011. 
TRINIDAD, Jamie. Self-Determination in Disputed Colonial Territories. Cambridge, New York: Cambridge University Press, 2018.

VARELLA, Marcelo D. Direito Internacional Público. São Paulo: Saraiva, 2009.

ZIEMANN, Daniela. 1966: África do Sul perdia o protetorado da Namíbia. DW. S/d. Disponível em: https://www.dw.com/pt-br/1966-\%C3\%A1frica-do-sul-perdia-o-protetorado-da-nam\%C3\%ADbia/a-314107. Acesso em: 25 mar. 2021.

\section{ADRIANO ALBERTO SMOLAREK}

Doutorando e Mestre em Ciências Sociais Aplicadas pela Universidade Estadual de Ponta Grossa. Membro Honorário do Núcleo de Estudos em Tribunais Internacional da Universidade de São Paulo (NETI-USP). Docente do curso de Direito da Universidade Estadual de Ponta Grossa (UEPG).

Endereço profissional: Praça Santos Andrade, 01 - Centro, Ponta Grossa - PR, 84010-330, Brasil.

Orcid id: https://orcid.org/0000-0003-0797-4409

E-mail: smolarek01@gmail.com

\section{JOÃO IRINEU DE RESENDE MIRANDA}

Doutor e Mestre em Direito Internacional pela Universidade de São Paulo. Docente e Coordenador do Programa de Pós-Graduação em Ciências Sociais Aplicadas da Universidade Estadual de Ponta Grossa (PPGCSA-UEPG). Docente do Curso de Direito na Universidade Estadual de Ponta Grossa.

Endereço profissional: Praça Santos Andrade, 01 - Centro, Ponta Grossa - PR, 84010-330, Brasil.

Orcid id: http://orcid.org/0000-0003-1838-6610

E-mail: joaoirineu78@gmail.com 
Recebido: 23/07/2020

Aceito: $18 / 01 / 2022$

\section{(c) $\underset{\mathrm{BY}}{(i)}$}

Este trabalho está licenciado sob uma licença Creative Commons Attribution 4.0 International License.

Autores e autoras cedem à Revista Sequência direitos exclusivos de primeira publicação, ficando o trabalho licenciado sob a Creative Commons Attribution 4.0 International License. A licença autoriza que terceiros remixem, adaptem e ou criem a partir do trabalho publicado, indicando o crédito ao trabalho original e sua publicação inicial. Os autores têm permissão para assumir contratos adicionais em separado, com distribuição não exclusiva da versão publicada na Revista Sequência, indicando, de todo modo, a autoria e publicação inicial neste periódico. 